\title{
Persistent digital divide in health-related internet use among cancer survivors: findings from the Health Information National Trends Survey, 2003-2018
}

\author{
Naleef Fareed $^{1,2} \cdot$ Christine M. Swoboda $^{1} \cdot$ Pallavi Jonnalagadda $^{1,2} \cdot$ Timothy R. Huerta $^{1,2,3}$ \\ Received: 11 March 2020 / Accepted: 7 July 2020 / Published online: 15 July 2020 \\ (C) Springer Science+Business Media, LLC, part of Springer Nature 2020
}

\begin{abstract}
Purpose Prior research on the use of the internet among cancer survivors indicates a digital divide. The online landscape and patterns of information consumption, however, have notably changed over the past decade necessitating an updated examination of health-related internet use (HRIU) among cancer survivors.

Methods Using survey data from 2003, 2005, 2007, 2011, 2013, 2017, and 2018 Health Information National Trends Survey (HINTS) iterations, the objectives of this study were to report prevalence, trends, and user profiles in HRIU in terms of emailing doctors, buying medicine online, and support group participation. Descriptive analyses and weighted multivariate logistic regression analyses were performed.

Results Cancer survivors who reported not using the internet were more likely to be older, belong to ethnic minorities, be less educated, and reside in rural areas as compared with those who reported using the internet. Except for participation in online support groups, all other types of HRIU increased in prevalence across the years.

Conclusions Consistent with the increased penetration of the internet and the altered online health communication landscape, we found increased prevalence of HRIU among cancer survivors. However, the digital divide persists in terms of internet access. These findings can inform initiatives to bridge the gap among survivors of varying profiles in using the internet for their health needs.

Implications for Cancer Survivors There is increased reliance on online platforms to obtain and communicate health-related information. The risk with this approach is potential oversight of ensuring equity in terms of internet access and technology literacy among survivors.
\end{abstract}

Keywords Internet $\cdot$ Cancer survivors $\cdot$ Disparities $\cdot$ Health information $\cdot$ Information sources $\cdot$ Health communication $\cdot$ Health promotion

Electronic supplementary material The online version of this article (https://doi.org/10.1007/s11764-020-00913-8) contains supplementary material, which is available to authorized users.

Naleef Fareed

Naleef.Fareed@osumc.edu

Christine M. Swoboda

Christine.Swoboda@osumc.edu

Pallavi Jonnalagadda

Pallavi.Jonnalagadda@osumc.edu

Timothy R. Huerta

Timothy.Huerta@osumc.edu
1 CATALYST - The Center for the Advancement of Team Science, Analytics, and Systems Thinking, College of Medicine, The Ohio State University, 460 Medical Center Drive, Columbus, OH 43210 , USA

2 Department of Biomedical Informatics, College of Medicine, The Ohio State University, 1585 Neil Avenue, Columbus, OH 43210, USA

3 Department of Family Medicine, College of Medicine, The Ohio State University, 2231 North High Street, Columbus, OH 43201, USA 


\section{Introduction}

The 2010s have been marked by an altered online landscape. The internet has emerged as the primary resource for healthrelated information for an increasing percentage of the population [1]. The internet is considered a conduit for extensive information, convenient access to specific types of information, and interactive communication for real-time feedback [1-4]. Thirty-five percent of US adults reported going online to diagnose a medical condition either for themselves or for someone else. Of those diagnosing themselves online, $46 \%$ sought medical attention based on the information they found. Furthermore, $41 \%$ of those diagnosing themselves online claimed that their diagnoses were confirmed by a medical professional [3]. In a 2012 Pew survey, 26\% of US adults reported having read about or watched another person's health experience and $16 \%$ reported going online to find others who shared their health concern [5]. The Health Information Technology for Economic and Clinical Health (HITECH) Act of 2009 [6], incentivized payments to eligible providers to meet Meaningful Use mandates heralding a new era in how healthcare is delivered in the USA [6]. Health Information Technology (HIT) like electronic health records (EHRs) and technologies like mobile applications, social media, and video conferencing have been increasingly adopted since 2013 [7] effectively transforming the online health communication landscape over the last decade [8]. In 2018, social media overtook traditional print media as the primary source of news [9]. According to a 2019 Pew Research Center survey, nine out of 10 adults went online, $81 \%$ owned a smartphone, and $72 \%$ used social media [10]. As connectedness becomes the standard expectation of individuals in the broader community, the implications of internet use and the associated disparities are critical to our understanding of cancer survivorship.

The number of cancer survivors is projected to increase to 20 million by 2026 [11]. The internet as a source of information was second only to the healthcare provider for cancer survivors $[12,13]$. Cancer survivors may use the internet for the following reasons: for information pertaining to disease management, complementary and alternative medicines, clinical trials and research, nutrition, personal rights, and medical language; for support in terms of advice on the cancer experience, emotional support, alleviation of isolation, and social interactions; and lastly, for practical reasons like communication with healthcare professionals, prescription refills, and scheduling. Reasons precluding cancer survivors from using the internet cited in the literature include lack of computer skills, lack of access to computers, concerns over privacy, and quality of information [14].

Chou and colleagues have documented an increasing trend in health-related internet use (HRIU) among cancer survivors, which they defined as emailing doctors, buying medicine online, online support group participation, and seeking cancer information from the internet as the first source [15]. Notably, they found that cancer survivors not using the internet were more likely to be less educated, belong to racial/ethnic minorities, live in non-metropolitan areas, and report worse general health suggesting a digital divide - defined as the gulf between people who have and do not have access to information technologies [16].

Since the report on HRIU among cancer survivors by Chou and colleagues, the online landscape has considerably shifted, where $90 \%$ of Americans reported using the internet compared with the year 2000, when nearly half the American adult population did not use the internet, per a 2019 report from the Pew Research Center [17]. In the general US population, the use of the internet as the first source for health information has risen across the years $[1$, 18]. Upon examining the individual types of HRIU in cancer survivors, Chou and colleagues found a significant trend across the years for all types of HRIU except cancer information seeking. In their study on cancer survivors, while they did not examine cancer information seeking on the internet, Jiang and Liu reported a rising trend in Internet Health Information Seeking (IHIS), defined as having looked for medical information on the internet for oneself or someone else in the past 12 months [19]. Another recent study on online patient provider communication (OPPC), which includes emailing doctors, among cancer survivors reported a rising trend from 2008 to 2017 [8]. These reports suggest a shrinking, yet persistent, digital divide. Long-term cancer survivors reported a high prevalence of unmet information needs pertaining to side effects and symptoms, test and treatment, health promotion, interpersonal and emotional, insurance, and sexual functioning and fertility [20]. Engagement in HRIU was associated with psychological benefits for survivors and was positively associated with the patient-provider relationship [21-23]. Therefore, it is of vital importance to understand the factors associated with HRIU to identify user profiles for developing tailored health promotion and communication strategies.

The current landscape is characterized by use of personalized technology and the internet of things influencing the dissemination of health information, HIT, and how patients and providers interact [7] highlighting the importance of updated information on trends in internet usage in the cancer survivor population. Therefore, the objectives of this analysis were to replicate and update the findings by Chou and colleagues [15] using a pooled, cross-sectional analysis based on data over multiple Health Information National Trends Survey (HINTS) iterations to examine prevalence, trends in HRIU, and user profiles of cancer survivors across the years. To this end, we used a combined sample of survey data from HINTS corresponding to 2003, 2005, 2007, 2011, 2013, 2017, and 2018. 


\section{Methods}

\section{Data collection}

This study used data obtained through HINTS [24] sponsored by the National Cancer Institute (NCI). HINTS is fielded to a representative sample of US civilian, non-institutionalized adults over 18 years of age. HINTS collects data about how respondents seek and use information about cancer, as well as cancer risk perception, cancer prevention behavior, and demographics. This study used data from HINTS 1 (2003), HINTS 2 (2005), HINTS 3 (2007), HINTS 4, cycles 1 (2011) and 3 (2013), and HINTS 5, cycles 1 (2017) and 2 (2018). The HINTS 1 and 2 surveys collected data by random-digitdialing respondents to participate in a telephone interview, while HINTS 3 in 2007 used two modes: random-digitdialing and also a mailed questionnaire. No differences were detected between survey administration modes based on chisquare comparison of key variables (i.e., age and gender), resulting in combining both telephone and mailed survey responses for HINTS 3. The fourth and fifth iterations of HINTS were administered by mail. The survey uses a stratified postal address frame to randomly sample residential addresses. HINTS is published with survey weights to allow the results to be more generalizable to the population [25].The response rates for each year were HINTS 1 (33\%), HINTS 2 (21\%), HINTS 3 (21\% telephone mode, $31 \%$ mail mode), HINTS 4 cycle1 (40\%), HINTS 4 cycle $3(35 \%)$, HINTS 5 cycle 1 (32\%), and HINTS 5 cycle $2(33 \%)$.

To facilitate comparison with the findings identified by Chou et al. [15], Tables 2 and 4 have analyses by year. Following Chou's approach, analyses controlled for gender, age, race/ethnicity, education level, rural/urban status, insurance status, general health status, and time since cancer diagnosis. In contrast to Chou et al., distress was removed as a covariate, as this was not collected after HINTS 3 in 2007. In addition, the first source of cancer information was not asked after 2007 and was removed as a dependent variable.

\section{Measures}

The main population of interest was cancer survivors, consisting of those who answered "Yes" to the question "Have you ever been diagnosed as having cancer?" Sociodemographic and clinical characteristics used as covariates in this analysis included gender (male/female), age (1849/50-64/65+), race/ethnicity (Hispanic/non-Hispanic White/ non-Hispanic Black/Other), education (high school graduate or less/some college/bachelor's degree or more), metropolitan status (metro area/non-metro area), general health (excellent, very good, or good/fair or poor), insurance status (insured/ uninsured), and time since diagnosis ( 1 year or less/2-5 years/ $6-10$ years/ $11+$ years).
Dependent variables used in this analysis include internet use, emailing doctors, buying medicine online, internet support groups, and seeking any cancer information. Internet use behavior was quantified by asking "Do you ever go on-line to access the Internet or World Wide Web, or to send and receive e-mail?" with responses of "Yes," or "No." If people responded "Yes" to using the internet at all, the ways people used the internet were assessed using the question "In the last 12 months, have you used the Internet for any of the following reasons?". Options included in this analysis were responses to the following: "used e-mail or the Internet to communicate with a doctor or a doctor's office" (emailing doctors), "bought medicine or vitamins online" (buying medicine online), and "participated in an online forum or support group for people with a similar health or medical issue" (support group). Finally, responses to the question "Have you ever looked for information about cancer from any source?" were included as a dependent variable in this analysis.

\section{Statistical analysis}

All analyses used survey weighting and jackknife variance estimations provided by HINTS to minimize sampling error [25]. Analyses were first performed using the data from 2003, 2005, and 2007 to replicate the findings from Chou et al. [15] to ensure model fidelity. These analyses were then extended to the 2011, 2013, 2017, and 2018 HINTS iterations.

Maintaining fidelity to the analyses conducted by Chou et al., the data was analyzed using the same demographic categories, excluding distress. Weighted descriptive statistics were analyzed for respondents who had a history of cancer and answered the question about internet use. Chi-square tests were used to test for associations between demographic characteristics and internet use. A weighted multivariable logistic regression model was created to explore the adjusted association between the dependent variables regarding HRIU, and the covariates gender, age, race/ethnicity, education, metro status, general health status, insurance status, and time since diagnosis among cancer survivors. Respondents excluded from regression analysis were those without any cancer history and/or those that did not answer the question regarding internet use. For the dependent variables pertaining to HRIU, the regression analysis excluded those who did not use the internet. Additionally, using the full sample of those who responded "Yes" to using the internet, we carried out Chi-square tests to test for associations between survey year and HRIU variables, and associations between cancer survivor status (cancer survivor, family with cancer but no personal history, and no history or family members with cancer) and HRIU variables. All analyses were completed using Stata version 14.2 (2015, StataCorp LP, College Station, Texas). 


\section{Results}

\section{Population}

A population sample was obtained from the combined 2003, 2005, 2007, 2011, 2013, 2017, and 2018 HINTS data. The response rate in the combined sample was $28.4 \%$. A total of 4756 respondents included in these analyses were cancer survivors and answered positively to the question regarding internet use (Table 1). While 2857 of the survivors used the internet across the sample, 1887 responded "No" when asked if they went online for any reason. There were 12 respondents with a history of cancer that did not answer the internet use question (i.e., we used data from 4744 respondents for our analysis of HRIU among cancer survivors). Unadjusted, bivariate analyses produced significant associations between
Table 1 Demographic characteristics of cancer survivors overall and by internet use in the pooled sample

\begin{tabular}{|c|c|c|c|c|}
\hline Characteristic & $\begin{array}{l}\text { Total } \\
(n=4756)^{\mathrm{a}}\end{array}$ & $\begin{array}{l}\text { Internet users } \\
(n=2857)\end{array}$ & $\begin{array}{l}\text { Non-internet users } \\
(n=1887)\end{array}$ & $p$ value \\
\hline Age & & & & $<0.001$ \\
\hline $18-49$ & $654(18.7)$ & $526(23.5)$ & $128(10.3)$ & \\
\hline $50-64$ & $1467(32.5)$ & $1098(39.3)$ & $366(20.7)$ & \\
\hline $65+$ & $2562(47.3)$ & $1200(35.8)$ & $1354(67.3)$ & \\
\hline Missing & $73(1.5)$ & $33(1.4)$ & $39(1.8)$ & \\
\hline Gender & & & & 0.876 \\
\hline Male & 1749 (41.4) & $1080(41.1)$ & $665(42.0)$ & \\
\hline Female & $2962(58.6)$ & $1751(58.9)$ & $1204(58.0)$ & \\
\hline Race/ethnicity & & & & $<0.001$ \\
\hline Hispanic & $252(5.7)$ & $125(4.6)$ & $126(7.8)$ & \\
\hline NH White & $3629(76.1)$ & $2295(80.2)$ & $1328(69.1)$ & \\
\hline NH Black & $330(6.6)$ & $170(5.5)$ & $160(8.5)$ & \\
\hline Other & $196(4.0)$ & $106(3.8)$ & $88(4.2)$ & \\
\hline Missing & $349(7.6)$ & $161(6.0)$ & $185(10.4)$ & \\
\hline Education & & & & $<0.001$ \\
\hline High school or less & $1668(40.0)$ & $586(25.7)$ & $1077(64.9)$ & \\
\hline Some college & $1349(30.1)$ & $888(35.1)$ & $457(21.3)$ & \\
\hline Bachelor's or more & $1631(27.4)$ & $1346(37.8)$ & $284(9.4)$ & \\
\hline Missing & $108(2.6)$ & $37(1.5)$ & $69(4.4)$ & \\
\hline Metro status & & & & $<0.001$ \\
\hline Metro area & $3857(81.3)$ & $2410(84.3)$ & $1436(76.1)$ & \\
\hline Non-metro area & 899 (18.7) & 447 (15.7) & $451(23.9)$ & \\
\hline General health & & & & $<0.001$ \\
\hline $\begin{array}{l}\text { Excellent/very } \\
\text { good/good }\end{array}$ & $3484(72.0)$ & $2306(79.9)$ & $1172(58.4)$ & \\
\hline Fair/poor & $1186(26.2)$ & $519(19.1)$ & $662(38.4)$ & \\
\hline Missing & $86(1.8)$ & $32(1.0)$ & $53(3.2)$ & \\
\hline Insurance & & & & $<0.001$ \\
\hline Insured & $4443(93.0)$ & $2693(94.4)$ & $1740(90.6)$ & \\
\hline Not insured & $213(4.9)$ & $120(4.1)$ & $92(6.3)$ & \\
\hline Missing & $100(2.1)$ & $44(1.5)$ & $55(3.2)$ & \\
\hline Time since diagnosis & & & & 0.034 \\
\hline Less than 1 year & $573(13.0)$ & $350(12.8)$ & $222(13.3)$ & \\
\hline $2-5$ years & $1104(23.8)$ & $706(25.3)$ & 397 (21.2) & \\
\hline $6-10$ years & $902(18.3)$ & $544(18.3)$ & $357(18.4)$ & \\
\hline 11 or more years & $1988(40.5)$ & $1173(40.0)$ & 807 (41.1) & \\
\hline Missing & $189(4.5)$ & $84(3.5)$ & $104(6.1)$ & \\
\hline
\end{tabular}

${ }^{a}$ There were 12 cancer survivors who did not indicate whether or not they used the internet. Their results were only included in the total column 
internet use and seven of the weighted factors: age $\left(X^{2}(6)=\right.$ $454.04, p<0.0001)$, race $\left(X^{2}(8)=101.64, p<0.0001\right)$, education $\left(X^{2}(6)=864.63, p<0.0001\right)$, metro status $\left(X^{2}(2)=\right.$ $49.82, p<0.0001)$, general health status $\left(X^{2}(4)=266.00\right.$, $p<0.0001)$, insurance status $\left(X^{2}(4)=35.61, p=0.0007\right)$, and time since diagnosis $\left(X^{2}(8)=28.44, p=0.0339\right)$.

\section{Health-related internet use across years}

There were significant associations between internet use, emailing doctors, buying medicine online, and seeking any cancer information and survey years (Table 2). All dependent variables increased in prevalence across survey years with the exception of online support group participation. The percent that answered "Yes" to internet use ranged from $49.3 \%$ in 2005 to $76.9 \%$ in 2017 , emailing doctors ranged from $9.4 \%$ in 2003 to $39.9 \%$ in 2013 , buying medicine online had a low of $11.4 \%$ in 2003 and a high of $24.9 \%$ in 2017, support group participation was at a low in 2005 of $3.5 \%$ and a high of $8.8 \%$ in 2003, and seeking cancer information from any source was $77.6 \%$ in 2007 and $89.8 \%$ in 2013.

\section{Health-related internet use by cancer status}

In the full sample that included all internet users $(n=31,491)$, there were significant associations between internet use, emailing doctors, online support group participation, and seeking any cancer information and cancer status (Table 3). Cancer survivors were the most likely to email doctors, be in online support groups, or seek cancer information online, while those with family who are survivors were most likely to use the internet. Those without a history of cancer or family members with cancer had the lowest prevalence of emailing doctors, buying medicine online, being in support groups, or seeking cancer info. Figures SF 1 to 5 in the supplementary document illustrate differences in responses between cancer survivors, those with family members with a history of cancer, and those with no history of cancer for the aforementioned HRIU questions over the study period.

\section{Health-related internet use by cancer survivor demographics}

Among cancer survivors, higher odds of internet use were associated with survey years 2007, 2011, 2013, 2017, and 2018 compared with 2003 (2007: OR 1.5, 95\% CI 1.0-2.0; 2011: OR 2.3, 95\% CI 1.6-3.1; 2013: OR 3.7, 95\% CI 2.45.8; 2017: OR 7.5, 95\% CI 5.0-11.2; and 2018: OR 4.8, 95\% CI 2.8-8.2) (Table 4). Younger adults, non-Hispanic white respondents, those with higher education levels, those living in metro areas, and those reporting excellent, very good, or good general health were more likely to use the internet. Respondents were more likely to email doctors in all survey 
Table 3 Internet use and healthrelated internet use by cancer status $(n=31,491)$

\begin{tabular}{lcllr}
\hline & Cancer survivors & $\begin{array}{l}\text { Family with } \\
\text { cancer }\end{array}$ & $\begin{array}{l}\text { No cancer and no family with } \\
\text { cancer }\end{array}$ & $p$ value \\
\hline Internet use & $63.5(61.4,65.6)$ & $77.8(76.9,78.7)$ & $69.4(67.7,71.0)$ & $<0.001$ \\
Emailing doctors & $28.7(26.4,31.1)$ & $24.3(23.1,25.5)$ & $22.8(21.0,24.7)$ & 0.008 \\
$\begin{array}{l}\text { Buying medicine } \\
\quad \text { online }\end{array}$ & $19.9(18.0,21.9)$ & $17.9(16.8,19.1)$ & $17.3(15.5,19.3)$ & 0.264 \\
Support group & $6.9(5.8,8.3)$ & $5.8(5.2,6.5)$ & $4.4(3.7,5.3)$ & 0.007 \\
Cancer info seeking & $82.9(80.9,84.8)$ & $60.8(59.7,61.9)$ & $38.9(36.7,41.0)$ & $<0.001$ \\
\hline
\end{tabular}

years compared with 2003, and emailing doctors was also associated with being younger, higher education levels, and living in metropolitan areas. Buying medicine online was more likely in all survey years compared with 2003 and was associated with higher education levels and being insured. The odds of support group participation were significantly lower in 2005 (OR 0.4, 95\% CI 0.2-0.9) and among those with excellent/very good/good general health, and the odds were higher among younger adults. Finally, among survivors who use the internet, seeking cancer information from any source had higher odds in 2013 and 2017 and among more educated adults, and lower odds among male survey respondents.

\section{Discussion}

This study sought to replicate and update the findings of Chou and colleagues [15], by reporting prevalence, trends, and user profiles of HRIU across the survey years from 2003 to 2018 using data from HINTS 1 through HINTS 5. We found that, despite the widespread availability of the internet, there were cancer survivors who did not utilize the internet. Our updated findings indicated that cancer survivors, who use the internet, were younger, white, college educated, metro-dwelling, and more likely to report better self-rated health. It is noteworthy that once online there were no race/ethnic differences in HRIU among cancer survivors. Overall, our findings are similar to those reported by Chou and colleagues suggesting a persistent digital divide despite the altered online health communication landscape.

We found that the proportion of cancer survivors reporting internet use increased across the years ranging from $49.5 \%$ in 2003 to $76.9 \%$ in 2017. Survivors not using the internet belonged to groups that were older, had a high school education, were from ethnic minorities, resided in non-metropolitan areas, and reported poor or fair self-rated health. As in the original study by Chou et al., the time since cancer diagnosis was not associated with internet use and any type of HRIU likely due to a healthy volunteer bias in the HINTS sample. In our multivariable models, the odds of internet use were higher in every year after 2005 . With the exception of participation in online support groups, prevalence of all other types of HRIU increased across the years from 2003 to 2018. In multivariable models, the odds of emailing doctors and buying medicines online were greater for all years in comparison with 2003. Our analysis found cancer survivors having college education or higher were more likely to engage in all types of HRIU except participation in online support groups.

In our study, the proportion of cancer survivors emailing their doctors increased from a mere $9.4 \%$ in 2003 to $39.9 \%$ in 2013. We also found that younger age, metropolitan residence, and college education were significantly associated with emailing doctors in all years as compared with the year 2003 in multivariable models. In contrast to the findings by Chou et al., we found that being 50-64 years old was a significant predictor of emailing doctors among cancer survivors. OPPC, of which emailing doctors is a subtype, has emerged as an alternative and a complement to traditional patient-provider communication [26]. OPPC has been associated with enhanced clinical management and self-care, decreased healthcare expenditure, increased accessibility to information, and reduced office visits/phone contacts [27, 28]. The increasing trend for emailing doctors found in our study of cancer survivors was also seen in the general US population. A recent study using HINTS data from 2003 to 2013 found that OPPC among US adults rose from 7\% in 2003 to $30 \%$ in 2013 as well as a significant increase in the proportion of internet users communicating with their providers using email [29]. However, our findings also suggest a flatlining of the proportion of survivors emailing their doctors since 2013. This trend could be explained by the variety of other options available to patients like mobile applications, social media, video conferencing, and EHRs that have been increasingly adopted since 2013 [8], coincident with the Meaningful Use mandates of the HITECH Act $[6,30]$. Indeed, 14\% cancer survivors in 2017 reported using the secure messaging feature in the EHR and $18.5 \%$ used mobile-based applications to communicate with their healthcare providers [8]. In the same study, Jiang and colleagues examined the association of the dimensions of the digital divide with OPPC finding that physical internet access was significantly associated for all the years studied, cognitive access (health information overload, self-efficacy in health information seeking, and trust in online information) was not associated with OPPC, and the association with 
Table 4 Multivariate logistic regression of factors associated with internet use and health-related internet use among cancer survivors $(n=4744)$

\begin{tabular}{|c|c|c|c|c|c|}
\hline & Internet use $\mathrm{a}^{\mathrm{a}}$ & Emailing doctors ${ }^{\mathrm{b}}$ & Buying medicine online $\mathrm{e}^{\mathrm{b}}$ & Support group participation ${ }^{\mathrm{b}}$ & Seeking cancer information ${ }^{b}$ \\
\hline & OR $(95 \% \mathrm{CI})$ & OR $(95 \% \mathrm{CI})$ & OR $(95 \% \mathrm{CI})$ & OR $(95 \% \mathrm{CI})$ & OR $(95 \% \mathrm{CI})$ \\
\hline \multicolumn{6}{|l|}{ Survey year } \\
\hline 2003 & 1.0 & 1.0 & 1.0 & 1.0 & 1.0 \\
\hline 2005 & $1.0(0.7-1.3)$ & $1.7(1.1-2.8)$ & $1.4(0.7-2.5)$ & $0.4(0.2-0.9)$ & $1.0(0.5-1.7)$ \\
\hline 2007 & $1.5(1.0-2.0)$ & $2.0(1.2-3.4)$ & $2.3(1.4-4.0)$ & $1.1(0.5-2.5)$ & $0.8(0.5-1.2)$ \\
\hline 2011 & $2.3(1.6-3.1)$ & $3.2(1.9-5.7)$ & $2.0(1.1-3.5)$ & $0.7(0.3-1.9)$ & $1.0(0.5-1.9)$ \\
\hline 2013 & $3.7(2.4-5.8)$ & $8.2(4.8-14.1)$ & $2.1(1.0-4.4)$ & $1.3(0.4-4.1)$ & $2.6(1.4-5.0)$ \\
\hline 2017 & $7.5(5.0-11.2)$ & $11.3(7.1-17.9)$ & $3.5(1.9-6.4)$ & $1.6(0.7-3.5)$ & $1.8(1.0-3.3)$ \\
\hline 2018 & $4.8(2.8-8.2)$ & $11.1(6.7-18.4)$ & $2.9(1.5-5.4)$ & $1.4(0.6-3.2)$ & $0.8(0.5-1.5)$ \\
\hline \multicolumn{6}{|l|}{ Age } \\
\hline $65+$ & 1.0 & 1.0 & 1.0 & 1.0 & 1.0 \\
\hline $50-64$ & $4.9(3.8-6.3)$ & $1.9(1.3-2.7)$ & $1.1(0.7-1.5)$ & $2.3(1.3-3.8)$ & $1.4(0.9-2.1)$ \\
\hline $18-49$ & $8.8(5.9-13.1)$ & $2.1(1.4-3.1)$ & $1.2(0.8-1.8)$ & $4.2(2.1-8.6)$ & $1.2(0.7-1.8)$ \\
\hline \multicolumn{6}{|l|}{ Gender } \\
\hline Female & 1.0 & 1.0 & 1.0 & 1.0 & 1.0 \\
\hline Male & $1.0(0.8-1.2)$ & $1.1(0.8-1.6)$ & $0.9(0.6-1.2)$ & $0.7(0.4-1.2)$ & $0.7(0.5-1.0)$ \\
\hline \multicolumn{6}{|l|}{ Race/ethnicity } \\
\hline Hispanic & 1.0 & 1.0 & 1.0 & 1.0 & 1.0 \\
\hline NH White & $3.2(1.6-6.5)$ & $1.5(0.8-3.0)$ & $1.4(0.8-2.7)$ & $0.9(0.2-3.8)$ & $2.0(0.8-4.7)$ \\
\hline NH Black & $1.4(0.7-3.1)$ & $1.2(0.5-3.1)$ & $0.9(0.3-2.5)$ & $0.5(0.1-2.4)$ & $1.7(0.5-5.4)$ \\
\hline Other & $1.9(0.8-4.4)$ & $2.2(0.8-5.8)$ & $2.3(0.8-7.1)$ & $1.4(0.2-9.3)$ & $1.6(0.4-6.5)$ \\
\hline \multicolumn{6}{|l|}{ Education } \\
\hline High school or less & 1.0 & 1.0 & 1.0 & 1.0 & 1.0 \\
\hline Some college & $3.2(2.4-4.3)$ & $2.7(1.6-4.5)$ & $1.8(1.2-2.9)$ & $1.5(0.7-3.3)$ & $2.3(1.5-3.6)$ \\
\hline Bachelor's or more & $7.6(6.0-9.6)$ & $3.2(2.2-4.8)$ & $1.7(1.2-2.5)$ & $1.2(0.6-2.2)$ & $3.0(1.9-4.7)$ \\
\hline \multicolumn{6}{|l|}{ Metro status } \\
\hline Non-metro area & 1.0 & 1.0 & 1.0 & 1.0 & 1.0 \\
\hline Metro area & $1.5(1.1-1.9)$ & $1.8(1.2-2.7)$ & $1.1(0.7-1.7)$ & $1.0(0.6-1.7)$ & $1.0(0.6-1.5)$ \\
\hline \multicolumn{6}{|l|}{ General health } \\
\hline Fair/poor & 1.0 & 1.0 & 1.0 & 1.0 & 1.0 \\
\hline Excellent/very good/good & $2.1(1.6-2.7)$ & $0.9(0.6-1.4)$ & $0.8(0.6-1.2)$ & $0.5(0.3-0.8)$ & $0.7(0.4-1.0)$ \\
\hline \multicolumn{6}{|l|}{ Insurance status } \\
\hline Not insured & 1.0 & 1.0 & 1.0 & 1.0 & 1.0 \\
\hline Insured & $1.6(0.9-2.7)$ & $1.9(0.8-4.7)$ & $2.8(1.1-7.5)$ & $1.2(0.3-4.4)$ & $1.2(0.7-2.3)$ \\
\hline \multicolumn{6}{|l|}{ Time since diagnosis } \\
\hline $11+$ years & 1.0 & 1.0 & 1.0 & 1.0 & 1.0 \\
\hline $6-10$ years & $1.0(0.8-1.4)$ & $1.1(0.7-1.6)$ & $1.2(0.8-1.8)$ & $1.2(0.6-2.4)$ & $1.4(0.9-2.2)$ \\
\hline $2-5$ years & $1.1(0.8-1.5)$ & $1.1(0.8-1.6)$ & $1.0(0.7-1.5)$ & $1.0(0.5-2.0)$ & $1.5(1.0-2.2)$ \\
\hline Less than 1 year & $1.1(0.8-1.5)$ & $1.4(0.9-2.1)$ & $1.1(0.7-1.7)$ & $0.7(0.3-1.4)$ & $1.3(0.7-2.3)$ \\
\hline
\end{tabular}

${ }^{\text {a }}$ Among cancer survivors

${ }^{\mathrm{b}}$ Among cancer survivors who used the internet

sociodemographic access (age, gender, race, household income, education, and health status) varied across the years.

Over the years, participation in support groups has consistently remained low compared with other types of HRIU. We did find that survivors younger than 65 were more likely to participate in online support groups than their older counterparts. Sharing experiences online may affect a person's health through finding information, feeling supported, maintaining relationships with others, affecting behavior, experiencing health services, learning to tell the story, and visualizing disease [31]. Research on social media participation, a contemporary platform for support groups, using 
HINTS data arrived at a similar conclusion and highlighted the lack of popularity of this medium [32]. More research is needed to understand the evolution of this medium to gain a better understanding of how social media-type interventions can be used to target age-based diseases such as cancer and how social support is expressed via social media. Previous research has indicated that these platforms as a source of support for cancer may be too general and more emotionally oriented (as opposed to focused on resources/needs) [33]. Popular social media outlets such as Facebook may also provide information that needs to be appraised for quality to ensure that it is evidence based [34, 35]. Recent developments in online support group platforms include patient-generated health-data cohorts, where cancer survivors can report health data and experiences through their mobile and wearable health devices [36]. Information collected on such platforms is also used to develop a knowledge base that would help future cancer survivors.

The proportion of survivors buying medicines online has steadily risen from $11.4 \%$ in 2003 to $24.9 \%$ in 2017 . There was no difference in the prevalence of buying medicines online by cancer status in our analysis. However, our results showed that cancer survivors who purchase medicines online were more likely to be insured after adjusting for sociodemographic factors and time since diagnosis. In a previous study, consumers of online pharmacies were more likely to be male, younger, white, married, more educated, and wealthier [37]. Buying medicine online offers several advantages: convenience to those who are housebound or disabled; privacy that encourages potentially embarrassing questions; variety; and affordable prices [38-40]. It also allows consumers to compare prices across internet pharmacies; for instance, a study showed that Americans can save nearly $24 \%$ per unit of drug if they purchase from an online Canadian pharmacy instead of an online US pharmacy [41].

In regard to cancer information seeking among cancer survivors, in contrast to Chou et al., we found that the frequency of cancer information seeking increased over time. It should be noted that the HINTS survey is altered and no longer asks the participant to distinguish cancer information seeking from the internet or any other source. Seeking cancer information online has been shown to be associated with engaging in protective behaviors like using sunscreen and increased adherence to screening guidelines [42]. In a survey of adult cancer patients at an academic medical center, $80 \%$ reported having internet access and $63 \%$ reported using the internet to search cancer-related information. Internet use to seek information about cancer differed by age, race, and education. The leading reason cited for an internet search was to develop questions to discuss with the provider. The top three types of information sought were treatment options, prognosis, and side effects. Results of the internet search influenced choice of treatment, choice of doctor, and enrollment in clinical trials [43]. A recent study examining IHIS (i.e., having looked for medical information on the internet for oneself or someone else in the past 12 months) in cancer survivors using data from the 2011, 2013, and 2017 iterations of HINTS [19] reported a rising trend for IHIS from $53.5 \%$ in 2011 to $69.2 \%$ in 2017 mirroring the trends in the general US population [44]. Despite an increase in the proportion of cancer survivors engaging in IHIS, the study confirmed a digital divide and further examined the dimensions of the digital divide: mental access (trust in online information and self-efficacy in health information seeking), material access (ease of internet access), skill access (skill to seek information online), and usage access (online healthrelated activities like emailing doctors and buying medicines). There was a significant positive association between IHIS and material access, usage access, and mental access (trust in online information) across all 3 years [19].

Our study findings have important implications for clinicians, researchers, and public health practitioners in light of the increased adoption of technologies like personal health record portals $[45,46]$ and the paradigm shift underway in response to the COVID-19 pandemic necessitating and fasttracking digital health solutions [47]. Evidence has shown that patient portals can foster patient engagement and improve health outcomes [48-51]. There is growing evidence of a digital divide in portal usage as younger, white cancer patients reportedly showed the heaviest use of patient portals [52]. Our updated results show that the persistent digital divide disproportionately affects vulnerable populations. Yet, while age, education, and residence were associated with HRIU, race and ethnic differences no longer exist among cancer survivors engaging in HRIU. As already emphasized by Chou et al., these findings underscore the importance of addressing the needs of a vulnerable population that is at risk of being further disenfranchised and potentially disengaged with their health and care [53].

Email has shown to be suited for questions about medications, health status updates, and medical questions [54], making it an important tool for patient-centered healthcare. Therefore, efforts should be made to encourage both patient and provider adoption of email and other types of OPPC. The slow and steady rise in buying medicine online offers several benefits to cancer survivors, such as, variety, better prices, and convenience. However, our findings suggest buying medicine online could contribute to disparities in health. The rising popularity of online pharmacies underscores a need to increase health literacy so consumers may make healthier choices and learn to recognize risks [55]. A systematic review of outcomes of online support and resources among cancer survivors showed a generally positive, albeit inconclusive, association [56]. Given the multitude of social media avenues available to people, the associated benefits, and the interactive nature of social media platforms, further research is needed to identify the profile of cancer survivors most likely to benefit 
from this medium. Prior evidence showed that the desire for information and the desire for participation in care are independent. Cancer patients can be classified as those who are involved in seeking information and healthcare decisions; those who seek information, but defer to their providers to make decisions; and those who prefer to delegate both the information gathering and decision-making to their providers [57]. However, the rising trend in cancer information seeking brings into focus the role of healthcare providers in guiding their patients' HRIU. Patients have expressed a desire for guidance from their primary care providers regarding medical information on the internet [58]; moreover, over time, there has been an upward trend in guided versus spontaneous use of the internet among cancer patients [59].

\section{Limitations and strengths}

Some of the strengths of this study include an examination of all the years of data making the results comparable with previous reports. Moreover, the health communication landscape has considerably altered in the past decade influencing the dissemination of health information, HIT, and how patients and providers interact [7] highlighting the importance of updated information on trends in internet usage in the cancer survivor population. However, there are some notable limitations. First, the data are based on self-report and subject to recall bias. Second, the surveyed population is subject to selection bias as respondents with poor prognosis and serious disease are less likely to participate in the survey. Third, our analysis does not account for type of cancer, which has been shown to be associated with cancer information seeking behavior [60]. Fourth, the data are cross-sectional precluding any inference on causation highlighting the need for other types of studies to complement results from surveys, for example, patterns of information use can be gleaned using internet search data [4] and mined from social media platforms [61] to explore questions about the specific topics discussed, relation between promotional information and discussions, and the relationship of these patterns to survey results from HINTS. Lastly, the response rate in HINTS was low, but it was similar in other national surveys [62, 63]. HINTS administrators have taken steps to minimize bias arising from modality, coverage, and sampling [64, 65].

\section{Implications}

Our findings suggest a persistent digital divide in vulnerable segments of the population. Compared with the year 2000, when nearly half the American adult population did not use the internet, $10 \%$ of US adults were offline per a 2019 report from the Pew Research Center. The offline US adults were more likely to be 65 and older, live in rural areas, and have a high school education [17]. Older adults in the general population have reported physical challenges in manipulating devices and a lack of confidence in using new technologies [66]. Trust in information and ease of searching for information were associated with adoption among older adults suggesting that this group might benefit from navigational assistance [67]. There is evidence showing significantly worse distress, depression, and overall health-related quality of life among Hispanic cancer patients [68]. In a recent study of online cancer prevention information seeking preferences in an ethnically diverse sample, older age, high school education, and being a Spanish speaker were associated with lower odds of seeking cancer prevention information online [69]. To avoid further exacerbating disparities, it is vital to gain an understanding of the perceptions of and barriers to internet access among older cancer survivors to inform the development of appropriate eliteracy interventions. However, it is noteworthy that once cancer survivors are online and engage in the different activities entailing HRIU, there were no significant race and ethnic differences highlighting the need to mitigate the barriers to internet access.

\section{Conclusion}

In summary, the current analysis using data from 5 iterations of HINTS showed increasing prevalence of HRIU among cancer survivors. Differences in internet use across key groups, particularly age, insurance status, and education, have implications for the design of health interventions and communication efforts.

Data availability This study uses publicly available data from the National Cancer Institute at hints.cancer.gov.

\section{Compliance with ethical standards}

Conflict of interest The authors declare that they have no conflict of interest.

\section{References}

1. Prestin A, Vieux SN, Chou WS. Is online health activity alive and well or flatlining? Findings from 10 years of the health information national trends survey. J Health Commun. 2015;20:790-8. https:// doi.org/10.1080/10810730.2015.1018590.

2. Fox S, Purcell K. Health Information | Pew Research Center. 2010. https://www.pewresearch.org/internet/2010/03/24/healthinformation/. Accessed 14 Jun 2020.

3. Fox S, Duggan M. Health Online 2013 | Pew Research Center. 2013. https://www.pewresearch.org/internet/2013/01/15/healthonline-2013/. Accessed 14 Jun 2020.

4. Ofran Y, Paltiel O, Pelleg D, Rowe JM, Yom-Tov E. Patterns of information-seeking for cancer on the internet: an analysis of real 
world data. PLoS One. 2012;7(9):e45921. https://doi.org/10.1371/ journal.pone.0045921.

5. Fox S. The social life of health information $\mid$ Pew Research Center. 2014. https://www.pewresearch.org/fact-tank/2014/01/15/thesocial-life-of-health-information/. Accessed 14 Jun 2020.

6. Blumenthal D. Implementation of the federal health information technology initiative. N Engl J Med. 2011;365(25):2426-31. https://doi.org/10.1056/NEJMsr1112158.

7. Blake KD, Chou W-YS, Prestin A, Hesse BW. Cancer prevention and control in the changing communication landscape. J Natl Cancer Inst Monographs. 2013;2013(47):131-2. https://doi.org/ 10.1093/jncimonographs/lgt032.

8. Jiang S, Hong YA, Liu PL. Trends of online patient-provider communication among cancer survivors from 2008 to 2017: a digital divide perspective. Journal of cancer survivorship : research and practice. 2019;13(2):197-204. https://doi.org/10.1007/s11764019-00742-4.

9. Shearer E. Social media outpaces print newspapers in the U.S. as news source | Pew Research Center. 2018. https://www. pewresearch.org/fact-tank/2018/12/10/social-media-outpacesprint-newspapers-in-the-u-s-as-a-news-source/. Accessed Jan 27 2020.

10. Schaeffer K. Key ways the U.S. changed in the 2010s | Pew Research Center. 2019. https://www.pewresearch.org/fact-tank/ 2019/12/20/key-ways-us-changed-in-past-decade/. Accessed Jan 272020.

11. Siegel RL, Miller KD, Jemal A. Cancer statistics, 2017. CA Cancer J Clin. 2017;67:7-30. https://doi.org/10.3322/caac.21387.

12. Mayer DK, Terrin NC, Kreps GL, Menon U, McCance K, Parsons SK, et al. Cancer survivors information seeking behaviors: a comparison of survivors who do and do not seek information about cancer. Patient Educ Couns. 2007;65:342-50. https://doi.org/10. 1016/j.pec.2006.08.015.

13. Shea-Budgell MA, Kostaras X, Myhill KP, Hagen NA. Information needs and sources of information for patients during cancer followup. Curr Oncol. 2014;21(4):165-73. https://doi.org/10.3747/co.21. 1932.

14. Holmes MM. Why people living with and beyond cancer use the internet. Integr Cancer Ther. 2019;18:1534735419829830. https:// doi.org/10.1177/1534735419829830.

15. Chou W-YS, Liu B, Post S, Hesse B. Health-related Internet use among cancer survivors: data from the Health Information National Trends Survey, 2003-2008. Journal of cancer survivorship : research and practice. 2011;5(3):263-70. https://doi.org/10.1007/ s11764-011-0179-5.

16. van Dijk J, Hacker K. The digital divide as a complex and dynamic phenomenon. Inf Soc. 2003;19(4):315-26. https://doi.org/10.1080/ 01972240309487.

17. Anderson MP, Andrew; Jiang, Jingjing; Kumar, Madhumita. $10 \%$ of Americans don't use the internet | Pew Research Center. 2019.

18. Finney Rutten LJ, Blake KD, Greenberg-Worisek AJ, Allen SV, Moser RP, Hesse BW. Online health information seeking among US adults: measuring progress toward a healthy people $2020 \mathrm{ob}-$ jective. Public Health Rep. 2019;134(6):617-25. https://doi.org/10. 1177/0033354919874074.

19. Jiang S, Liu PL. Digital divide and Internet health information seeking among cancer survivors: a trend analysis from 2011 to 2017. Psycho-Oncology. 2020;29(1):61-7. https://doi.org/10. 1002/pon.5247.

20. Kent EE, Arora NK, Rowland JH, Bellizzi KM, Forsythe LP, Hamilton AS, et al. Health information needs and health-related quality of life in a diverse population of long-term cancer survivors.
Patient Educ Couns. 2012;89(2):345-52. https://doi.org/10.1016/j. pec.2012.08.014.

21. Bylund CL, Gueguen JA, D'Agostino TA, Imes RS, Sonet E. Cancer patients' decisions about discussing Internet information with their doctors. Psycho-Oncology. 2009;18(11):1139-46. https://doi.org/10.1002/pon.1511.

22. McMullan M. Patients using the Internet to obtain health information: how this affects the patient-health professional relationship. Patient Educ Couns. 2006;63(1):24-8. https://doi.org/10.1016/j. pec.2005.10.006.

23. Murray E, Lo B, Pollack L, Donelan K, Catania J, White M, et al. The impact of health information on the internet on the physicianpatient relationship: patient perceptions. Arch Intern Med. 2003;163(14):1727-34. https://doi.org/10.1001/archinte.163.14. 1727.

24. National Cancer Institute. Survey Instruments. HINTS. https:// hints.cancer.gov/data/survey-instruments.aspx. Accessed 26 Feb 2020.

25. National Cancer Institute. Frequently Asked Questions. HINTS. https://hints.cancer.gov/about-hints/frequently-asked-questions. aspx. Accessed 12 Feb 2020

26. Richards R, Kinnersley P, Brain K, McCutchan G, Staffurth J, Wood F. Use of mobile devices to help cancer patients meet their information needs in non-inpatient settings: systematic review. JMIR mHealth uHealth. 2018;6:e10026. https://doi.org/10.2196/ 10026.

27. Reed M, Graetz I, Gordon N, Fung V. Patient-initiated e-mails to providers: associations with out-of-pocket visit costs, and impact on care-seeking and health. Am J Manag Care. 2015;21(12):e632-9.

28. Santana S, Lausen B, Bujnowska-Fedak M, Chronaki C, Kummervold PE, Rasmussen J et al. Online communication between doctors and patients in Europe: status and perspectives. Journal of medical Internet research. 2010;12(2):e20-e. doi: https://doi.org/10.2196/jmir.1281.

29. Tarver WL, Menser T, Hesse BW, Johnson TJ, Beckjord E, Ford EW, et al. Growth dynamics of patient-provider internet communication: trend analysis using the health information National Trends Survey (2003 to 2013). J Med Internet Res. 2018;20:e109. https:// doi.org/10.2196/jmir.7851.

30. Marcotte L, Seidman J, Trudel K, Berwick DM, Blumenthal D, Mostashari F, et al. Achieving meaningful use of health information technology: a guide for physicians to the EHR incentive programs. Arch Intern Med. 2012;172(9):731-6. https://doi.org/10.1001/ archinternmed.2012.872.

31. Ziebland SUE, Wyke S. Health and illness in a connected world: how might sharing experiences on the internet affect people's health? The Milbank Quarterly. 2012;90(2):219-49. https://doi. org/10.1111/j.1468-0009.2012.00662.x.

32. Huo J, Desai R, Hong Y-R, Turner K, Mainous AG, Bian J. Use of social media in health communication: findings from the health information national trends survey 2013, 2014, and 2017. Cancer Control. 2019;26(1):1073274819841442. https://doi.org/10.1177/ 1073274819841442 .

33. Mikal JP, Grande SW, Beckstrand MJ. Codifying online social support for breast cancer patients: retrospective qualitative assessment. J Med Internet Res. 2019;21(10):e12880.

34. Gage-Bouchard EA, LaValley S, Mollica M, Beaupin LK. Cancer communication on social media: examining how cancer caregivers use Facebook for cancer-related communication. Cancer Nurs. 2017;40(4):332-8.

35. Fareed N, M. SC, Jonnalagadda P, Walker DM, Huerta T. Differences between races in health information seeking and trust over time: evidence from a cross-sectional, pooled analyses of 
HINTS data. American Journal of Health Promotion (Forthcoming). 2020. doi:https://doi.org/10.1177/ 0890117120934609.

36. Perales M-A, Drake EK, Pemmaraju N, Wood WA. Social media and the adolescent and young adult (AYA) patient with cancer. Current hematologic malignancy reports. 2016;11(6):449-55.

37. Holiday-Goodman M, Darley WK, Lively BT, Siganga W, Deshmukh-Estoll HC. Investigation of consumer choice of community, mail order, or internet pharmacies. J Pharm Technol. 2007;23(1):16-22. https://doi.org/10.1177/875512250702300104.

38. Bruckel K, Capozzoli EA. Internet pharmaceutical sales: attributes, concerns, and future forecast. J Hosp Mark Public Relations. 2003;15(1):61-76. https://doi.org/10.1300/j375v15n01_06.

39. Fung CH, Woo HE, Asch SM. Controversies and legal issues of prescribing and dispensing medications using the Internet. Mayo Clin Proc. 2004;79(2):188-94. https://doi.org/10.4065/79.2.188.

40. Henney JE. Cyberpharmacies and the role of the US Food And Drug Administration. J Med Internet Res. 2001;3(1):E3. https:// doi.org/10.2196/jmir.3.1.e3.

41. Quon BS, Firszt R, Eisenberg MJ. A comparison of brand-name drug prices between Canadian-based internet pharmacies and major U.S. drug chain pharmacies. Ann Intern Med. 2005;143(6):397403. https://doi.org/10.7326/0003-4819-143-6-200509200-00004.

42. Wigfall LT, Friedman DB. Cancer information seeking and cancerrelated health outcomes: a scoping review of the health information national trends survey literature. J Health Commun. 2016;21(9): 989-1005. https://doi.org/10.1080/10810730.2016.1184358.

43. Castleton K, Fong T, Wang-Gillam A, Waqar MA, Jeffe DB, Kehlenbrink L, et al. A survey of Internet utilization among patients with cancer. Support Care Cancer. 2011;19(8):1183-90. https://doi. org/10.1007/s00520-010-0935-5.

44. Jacobs W, Amuta AO, Jeon KC. Health information seeking in the digital age: an analysis of health information seeking behavior among US adults. Cogent Social Sciences. 2017;3(1). doi:https:// doi.org/10.1080/23311886.2017.1302785.

45. Sarkar U, Karter AJ, Liu JY, Adler NE, Nguyen R, López A, et al. Social disparities in internet patient portal use in diabetes: evidence that the digital divide extends beyond access. J Am Med Inform Assoc. 2011;18(3):318-21. https://doi.org/10.1136/jamia.2010. 006015.

46. Ford EW, Hesse BW, Huerta TR. Personal health record use in the United States: forecasting future adoption levels. J Med Internet Res. 2016;18(3):e73. https://doi.org/10.2196/jmir.4973.

47. Gray DM, Joseph JJ, Olayiwola JN. Strategies for digital care of vulnerable patients in a COVID-19 world-keeping in touch. JAMA Health Forum. 2020.

48. Phelps RG, Taylor J, Simpson K, Samuel J, Turner AN. Patients' continuing use of an online health record: a quantitative evaluation of 14,000 patient years of access data. J Med Internet Res. 2014;16(10):e241. https://doi.org/10.2196/jmir.3371.

49. Tulu B, Trudel J, Strong DM, Johnson SA, Sundaresan D, Garber L. Patient portals: an underused resource for improving patient engagement. Chest. 2016;149(1):272-7. https://doi.org/10.1378/ chest.14-2559.

50. McAlearney AS, Fareed N, Gaughan A, MacEwan SR, Volney J, Sieck CJ. Empowering patients during hospitalization: perspectives on inpatient portal use. Appl Clin Inform. 2019;10(1):103-12. https://doi.org/10.1055/s-0039-1677722.

51. McAlearney AS, Sieck CJ, Gaughan A, Fareed N, Volney J, Huerta TR. Patients' perceptions of portal use across care settings: qualitative study. J Med Internet Res. 2019;21(6):e13126. https://doi.org/ $10.2196 / 13126$.
52. Gerber DE, Laccetti AL, Chen B, Yan J, Cai J, Gates S, et al. Predictors and intensity of online access to electronic medical records among patients with cancer. Journal of oncology practice / American Society of Clinical Oncology. 2014;10(5):e307-12. https://doi.org/10.1200/JOP.2013.001347.

53. Bush RA, Vemulakonda VM, Richardson AC, Deakyne Davies SJ, Chiang GJ. Providing access: differences in pediatric portal activation begin at patient check-in. Appl Clin Inform. 2019;10(4):670-8. https://doi.org/10.1055/s-0039-1695792.

54. Ye J, Rust G, Fry-Johnson Y, Strothers H. E-mail in patientprovider communication: a systematic review. Patient Educ Couns. 2010;80:266-73. https://doi.org/10.1016/j.pec.2009.09. 038.

55. Orizio G, Merla A, Schulz PJ, Gelatti U. Quality of online pharmacies and websites selling prescription drugs: a systematic review. J Med Internet Res. 2011;13(3):e74. https://doi.org/10.2196/jmir. 1795.

56. Hong Y, Peña-Purcell NC, Ory MG. Outcomes of online support and resources for cancer survivors: a systematic literature review. Patient Educ Couns. 2012;86(3):288-96. https://doi.org/10.1016/j. pec.2011.06.014.

57. Czaja R, Manfredi C, Price J. The determinants and consequences of information seeking among cancer patients. J Health Commun. 2003;8(6):529-62.

58. Diaz JA, Sciamanna CN, Evangelou E, Stamp MJ, Ferguson T. Brief report: what types of internet guidance do patients want from their physicians? J Gen Intern Med. 2005;20(8):683-5. https://doi. org/10.1111/j.1525-1497.2005.0115.x.

59. Lleras de Frutos M, Casellas-Grau A, Sumalla EC, de Gracia M, Borràs $\mathrm{JM}$, Ochoa Arnedo C. A systematic and comprehensive review of internet use in cancer patients: psychological factors. Psycho-Oncology. 2020;29(1):6-16. https://doi.org/10.1002/pon. 5194.

60. Nagler RH, Gray SW, Romantan A, Kelly BJ, DeMichele A, Armstrong $\mathrm{K}$, et al. Differences in information seeking among breast, prostate, and colorectal cancer patients: results from a population-based survey. Patient Educ Couns. 2010;81(Suppl): S54-62. https://doi.org/10.1016/j.pec.2010.09.010.

61. Zhang H, Wheldon C, Dunn AG, Tao C, Huo J, Zhang R, et al. Mining Twitter to assess the determinants of health behavior toward human papillomavirus vaccination in the United States. J Am Med Inform Assoc. 2020;27(2):225-35. https://doi.org/10.1093/jamia/ ocz191.

62. Fahimi M, Link M, Mokdad A, Schwartz DA, Levy P. Tracking chronic disease and risk behavior prevalence as survey participation declines: statistics from the behavioral risk factor surveillance system and other national surveys. Prev Chronic Dis. 2008;5(3):A80A.

63. Blumberg SJ, Luke JV, Cynamon ML. Telephone coverage and health survey estimates: evaluating the need for concern about wireless substitution. Am J Public Health. 2006;96(5):926-31. https:// doi.org/10.2105/ajph.2004.057885.

64. Cantor D, Coa K, Crystal-Mansour S, Davis T, Dipko S, Sigman R. Health information national trends survey (HINTS) 2007. Westat: Rockville; 2009.

65. Finney Rutten LJ, Davis T, Beckjord EB, Blake K, Moser RP, Hesse BW. Picking up the pace: changes in method and frame for the health information national trends survey (2011-2014). J Health Commun. 2012;17(8):979-89.

66. Anderson MP, Andrew. Barriers to adoption and attitudes towards tech among older Americans | Pew Research Center. 2017.

67. Miller LMS, Bell RA. Online health information seeking:the influence of age, information trustworthiness, and search challenges. 
Journal of Aging and Health. 2012;24(3):525-41. https://doi.org/ $10.1177 / 0898264311428167$.

68. Luckett T, Goldstein D, Butow PN, Gebski V, Aldridge LJ, McGrane J, et al. Psychological morbidity and quality of life of ethnic minority patients with cancer: a systematic review and meta-analysis. Lancet Oncol. 2011;12(13):1240-8. https://doi.org/10. 1016/S1470-2045(11)70212-1.
69. Ginossar T. Predictors of online cancer prevention information seeking among patients and caregivers across the digital divide: a cross-sectional. Correlational Study JMIR Cancer. 2016;2(1):e2. https://doi.org/10.2196/cancer.5108.

Publisher's note Springer Nature remains neutral with regard to jurisdictional claims in published maps and institutional affiliations. 